\title{
Robot at the Reference Desk?
}

\author{
Karen F. Smith
}

To enhance the productivity of reference librarians, libraries might consider ways to tap their expertise while the librarians themselves are off duty. This paper describes an experimental microcomputer program designed to provide reference assistance for federal documents in a separate government documents department during hours when the regular staff members are not available. By making choices from a series of menus the patron conducts his or her own reference interview and is given a short list of appropriate books to consult. Overcoming difficulties in the development of expert systems for use in reference work is discussed. These include carving out a discrete area of reference work to computerize, identifying the basic strategies or librarian tricks of the trade to incorporate, and providing a workable human/computer interface.

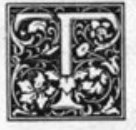

hese actual headlines-" Robot Performs Household Chores, ${ }^{\prime \prime}$ "Robot Chosen for Commencement Speaker,", "Robot Joins Police,",3 "Robot Nurse Reacts to Voice Requests,", "Robot Helps Perform Brain Surgery,", "Robot Documents Librarian to be Tested at University, ${ }^{\prime \prime}$ - are all, except the last one, probably factual. The robot librarian, unfortunately, is still just a dream.

I say "unfortunately" because a robot librarian might be just the thing to relieve us from overwork, burnout, boredom, and frustration. Academic reference librarians are caught up in a situation where there are too few people to do the work that needs to be done; the job keeps expanding; the reference sources proliferate; information retrieval becomes increasingly complex; and, in spite of all our efforts at bibliographic instruction, naive end users continue to parade through our turnstiles. We are committed to making our users "library literate" but how many times can you explain how to find periodicals in the library without sounding like a robot yourself?

Three years ago State University of New
York (SUNY) at Buffalo experienced severe staff cuts and I found myself the sole librarian in the government documents department. The department was open ninety hours per week. We had a collection of 350,000 items classified and shelved by Superintendent of Documents (SuDoc) numbers but not cataloged. Professors were asking for tours and bibliographic instruction sessions. What could I do? At first I tried to cope by depending more on the clerical staff and the student assistants to provide patron assistance. We hired graduate students to work nights and weekends. But, it soon became apparent that training student assistants to do reference work would be an endless, repetititve, and extremely timeconsuming task. It just didn't seem like an effective way to increase the productivity of the librarian.

At about the same time, articles on expert systems began to appear in computer journals. Artificial-intelligence research was beginning to pay off. Systems had been developed that could do real work and it seemed to me that this was exactly what the library world needed to liberate their experts.

Karen F. Smith is Head of the Documents and Microforms Department at the Lockwood Library, State University of New York, Buffalo, New York 14260. This paper was presented at the ACRL Fourth National Conference in Baltimore, April 9-12, 1986. 


\section{THE PROJECT}

If a computer could diagnose bacterial infections and prescribe treatment why couldn't a computer diagnose an information need and prescribe a reference book to solve the problem? Furthermore, the articles said that a secondary function of the expert system was training aspiring but neophyte experts, and I figured it would be easier to teach the student assistants how to tap into a computer system than to teach them everything I had learned during fifteen years of working with documents.

I had no idea how to create an expert system but I gathered from the articles that you needed a knowledge engineer. The knowledge engineer talks to experts about what they know and how they do their jobs. Expert systems are based on the premise that the problem-solving ability of the expert is an outgrowth of his or her knowledge base. If that knowledge can be identified and transferred to a computer then the computer can also solve problems. It is the knowledge engineer's job to extract the pertinent information from the expert's head and program the computer accordingly.

I found a professor in our computer science department who was involved in expert systems research. Surprisingly, he was interested in how reference librarians "do their thing" and he was willing to work with me on such a project. We got a small grant from the Council on Library Resources, hired a graduate student, and proceeded to investigate the feasibility of developing a computer-assisted government documents reference capability. By the end of the summer we had a program written in LISP, designed to be used by an ordinary person, which would lead the person through a decision process to pinpoint the most useful of the fifty or so reference books in the documents department for that person's particular need. Since then, the program has been translated into BASIC and runs on an IBM PC. We call it Pointer.

The system is limited, by design, to just one step in the reference process: the step where the reference librarian chooses a reference book to satisfy the patron's information need. We give the call number of the book and assume the patron can find it on the shelves and figure out how to use it. The reference interview is handled by providing an overview of governmentproduced information in the form of menus and letting the patron choose the area that most closely matches his or her inquiry. The basic choice is whether the person is looking for a specific document or looking for information on a topic. [See appendix $\mathrm{A}$ ].

\section{PROBLEMS}

Grappling with a real project such as this is a good way to experience firsthand the problems facing artificial-intelligence research. The first problem involves specifying a suitable domain for the expert system. The knowledge-based systems that have been developed up to now operate on a rather small body of facts as compared to the total body of recorded knowledge that is the domain of the general reference librarian. The librarian's ability to switch mental gears instantly and place each new inquiry in its proper context is a most difficult feat for the computer to replicate.

Expert systems operate in specialized, well-defined subject areas, whereas government publishing gets into all subject areas. So there was some question about whether government documents librarianship was a manageable domain for an expert system. I reasoned that the bibliographic knowledge of the documents librarian is less dependent on subject expertise than on other factors. Whether the librarian recommends using the Publication Reference File or the Monthly Catalog is not so much dependent on the topic of the inquiry as it is on factors such as the purpose of the inquiry, time period involved, or specificity of bibliographic information available to work with. Government documents is a specialty area within librarianship. It is an area often handled separately in research guides. Thus it seemed reasonable to try to develop an expert system to handle the types of questions fielded by the documents librarian. 
On the other hand, the domain must be complicated enough to make good use of the capabilities of the computer. If you can describe fifty document reference tools on a handout with a chart showing when to use what, why do you need a fancy computerized system? My premise is that people won't read the descriptions of fifty reference books. People want individualized attention. And they don't want to learn about CIS Index when what they need is ASI. Most librarians concede that government documents reference is complicated. You can make do with the Monthly Catalog if you have to but there are times when other tools do the job more quickly. We decided that a system that would direct a library patron to one or more of the fifty most-used reference tools in the documents department would be a system worth developing.

After you have specified the domain, the next problem is to identify the knowledge that one must have to operate in that domain. What does the expert need to know before making a decision? What are the facts that lead to a particular conclusion? What rules of thumb does the expert use? Most of us don't think about what we do, we just do it. So, figuring out how we do it can be a time-consuming, although valuable, process. There are those whobelieve that this is the most important aspect of expert-systems research. Capturing knowledge that has never before been written down is a contribution in and of itself. However, this transferring of knowledge from the human expert to the computer system is proving to be the bottleneck slowing down the advancement of expert-systems development. If the knowledge engineer is unfamiliar with the field of expertise, the process is even slower.

My knowledge engineer, a graduate student in computer science, had never worked on an expert system before so we proceeded in a rather ad hoc manner. Actually, we were not atypical. This whole field of endeavor is so new that there are few established methods. We had two things to work with: the list of reference tools and a collection of reference ques- tions asked in the department during the previous eighteen months. We operated from both ends toward the middle.

From the collection of reference questions we knew that the service we perform most often is helping people locate specific documents already known to them. In the case of federal documents this means identifying the SuDoc number; a relatively straightforward procedure when the title and date are known and easy to program. The more difficult task was dealing with requests for information on a topic, for that required providing a conceptual framework for the government documents domain. Branch of government, type of answer needed, time period, type of reference book-nothing was quite adequate and we never did solve this problem to our complete satisfaction. I felt I was delving into the fundamental mysteries of the universe. I still keep hoping for one of those "Ah ha!" experiences where the big picture suddenly becomes clear and all the pieces fall neatly into place.

However, in addition to the supply of reference questions, we also had our reference tools as a resource to guide us. We asked, "What is this book good for? What does it do?" Library card catalogs, for the most part, do not describe reference books adequately. The people who can benefit from CIS Index are not going to be looking in the subject catalog under Law-United States-Indexes. And how is the card United States-Statistics going to reveal the power of ASI Index? Even reference librarians sometimes have trouble finding sources in the card catalog when they know they exist but have forgotten the exact title. A computerized reference system lends itself to in-depth indexing to bring out the special features of every reference tool. Many reference books have secondary uses, hidden information that only the frequent user is aware of. The computer makes it possible to find those secret gems again because the computer never forgets. The computer will always remind the patron that the defunct agencies listed in appendix A of the U.S. Government Manual are not included in the index. Do you? 
By working with what the people wanted to know and with what the reference books had to offer, we developed an outline of government information resources that is pragmatic, if not elegant. The next big problem was how to communicate with the computer. Although there are computers on the market that respond to voice commands and there are computers that talk, science is very far from developing a computer system that can listen to a person's voice request and respond like a librarian. So, we used a simple menu based system for Pointer. Menu choices have the advantage of being readily understood by both people and computers. Expert systems that demand communication in a specialized language will not be appropriate for libraries.

Twenty years ago, Jesse Shera wrote about automation and the reference librar- ian. He said, "The important point . . . is that the machine problems per se are well on the way to solution; the great unsolved problems are those which are fundamental to the reference situation itself. In short, we can now build the machines . . . but we do not know how to use them intelligently in the reference library environment. The machines are ready for us, or very soon will be, but we are still very far from being ready for machines." believe, we are ready; not eager perhaps, but accepting of the fact that the computer will occupy a position of importance in the reference setting. Computers never get tired, or cross, or bored. They have the potential to provide a consistent, if minimal, level of service at the reference desk, freeing the librarian to work on problems requiring more creativity or demanding greater intellectual effort.

\section{REFERENCES}

1. Los Angeles Times 5:21 (June 22, 1984).

2. Washington Post 2:6 (May 1, 1983).

3. Los Angeles Times 2:1 (Jan. 20, 1984).

4. Buffalo News 2:11 (Apr. 14, 1985).

5. Buffalo News 1:8 (Apr. 18, 1985).

6. Library Journal $110: 30$ (Feb. 1, 1985).

7. Jesse Shera, "Automation and the Reference Librarian," RQ 3:7 (July 1964).

\section{RELATED READING}

McCorduck, Pamela. The Universal Machine: Confessions of a Technological Optimist (New York: McGraw-Hill, 1985).

Naylor, Chris. Build Your Own Expert System (Wilmslow, Cheshire, U.K.: Sigma Technical Press, 1983). Smith, Dana E., and Steve M. Hutton. "Back at 8:00 AM; Microcomputer Library Refernce Support Programs." Collegiate Microcomputer 2:289 (Nov. 1984).

\section{APPENDIX A: SAMPLE SEARCH}

Welcome to the Documents Department. This system will help you find reference books for U.S. documents. If you need New York State or Canadian documents, please see the librarian. The key to the federal documents collection is the Superintendent of Documents (SuDoc) number. The SuDoc number arranges documents on the shelves by issuing agency, not necessarily by subject. If you have a citation which includes the SuDoc number, you can proceed directly to the shelves. Otherwise you will be directed to various catalogs and indexes in the reference collection where SuDoc numbers can be located. The following are typical SuDoc numbers: EP 1.2:L44/3 Y4.G79/2:M64 LC 1.1:982. Do you wish to continue? Type 'yes' or 'no' and press RETURN. 


\section{YES}

Are you looking for:

1. a particular document for which you have a title?

2. a particular document for which you have some number such as a bill number?

3 . information on some subject?

Select your choice by entering 1,2 , or 3 and press RETURN

Do you want:

1. Biographical information?

2. Numeric data?

3. Laws concerning your subject?

4. Regulations concerning your subject?

5. Court cases concerning your subject?

6. Executive orders or presidential statements?

7. Information produced by the Congress?

8. Bills concerning your subject?

9. Names, addresses, or phone numbers?

10. Information contained in treaties?

11. Information in technical reports?

12. Information about grants, fellowships, or jobs?

13. Periodical articles?

14. General information from pamphlets or books?

15 . Something not covered above?

Select $1-15$ by entering the appropriate number, and press RETURN.

Use the following sources:

1. The Official Congressional Directory located in the reference collection, DOC REF JK1011. See the heading 'Biographies' in the front of the book and the Individual Index in the back. 2. The CIS Index located on the index table, DOC REF Z1223 A22. This reference tool can be used for information covering 1970 to the present. 3. The Congressional Record located in the reference collection and the stacks under SuDoc number X/(session of Congress). See the annual index for the year the person died, was appointed, or otherwise became prominent. 4. The Cumulative Subject Index to the Monthly Catalog located in the reference collection, DOC REF Z1223 A182. See the heading 'Biography' as well as the names of individuals. 5. The Biographical Directory of the American Congress located in the Lockwood reference collection, Ref JK1010 A5 1971. 6. The Congressional Staff Directory located in the reference collection, Ref JK1012 C66. 